\title{
Críticas a la originalidad del arte: usos de la repetición en la pintura de Pablo Siquier
}

Florencia Malbrán

New York University Buenos Aires - Argentina

\begin{abstract}
Resumo
O artigo explora a hipótese de que várias obras de arte contemporâneas sugerem uma revisão crítica de noçóes como originalidade, identidade e história(s), em oposição ao teoria da arte kantiana do "fim infinito" (em que os discursos teleológicos e modernos são suportados). Analisa, em particular, a trajetória do reconhecido artista argentino Pablo Siquier, cuja pintura se opóe aos discursos que buscam priorizar as condiçôes específicas de cada arte (o caráter único de pintura, escultura, literatura) e, assim, associaram a arte à pureza e originalidade. As obras de Siquier, em contrapartida, mostram interesse na multiplicidade, substituem o conceito de originalidade ou o de uma substância essencial, e questionam regimes de estrita classificação, promovendo uma nova abertura da arte ao mundo contemporâneo, um mundo que aceita a incerteza e a queda da certeza e do controle.

Palavras-chave: Pinturas contemporâneas; Multiplicidade; Originalidade; Abertura; Pablo Siquier.
\end{abstract}

\section{Resumen}

El trabajo explora la hipótesis de que varias obras de arte contemporáneas sugieren una revisión crítica de nociones como originalidad, identidad e historia(s), al contraponerse al estandarte kantiano de la "finalidad sin fin" (en el cual se enraizaron los relatos teleológicos y modernos). Se analiza en particular la trayectoria del reconocido artista argentino Pablo Siquier, cuya pintura se opone a los relatos que buscaron jerarquizar las condiciones específicas de cada arte (el carácter único de la pintura, la escultura, la literatura) y, así, asociaron el arte a la pureza y la originalidad. Las obras de Siquier manifiestan, en cambio, un interés por la multiplicidad, sustituyen el concepto de la originalidad o el de una sustancia esencial, y objetan los regímenes estrictos de clasificación, promoviendo una nueva apertura del arte al mundo contemporáneo, un mundo que acepta la incertidumbre y la caída de la certeza y el control.

Palabras clave: Pintura contemporánea; Multiplicidad; Originalidad; Apertura; Pablo Siquier. 
1 ESTOL, Leopoldo. "Entrevista", 2011, p. 69. En sintonía con este comentario, en el comienzo del libro Siquier, que revisa la trayectoria del artista y reproduce sus obras más significativas, se encuentra la siguiente aclaración: "Para la edición del presente volumen, se tomó como referencia la continuidad morfológica entre las diversas obras reproducidas, con independencia de la fecha en que fueron realizadas. El criterio surge de una observación que Pablo Siquier logró formular solo recientemente, según la cual, pese a sus más de veinte ańos de trabajo, el artista siente haber estado pintando siempre el mismo cuadro". TABAROVSKY, Damián. Pablo Siquier, 2011, p. 7.

2 Pablo Siquier en conversaciones conmigo, 16 de marzo de 2015.
La obra Pablo Siquier (Buenos Aires, 1961) hace posible cuestionar los relatos teleológicos de la historia del arte que trazaron para la pintura un progreso constante y lineal, auspiciando una batalla por la especialización en formas inenarrables o en la visualidad más pura, por lo tanto rechazando el discurso social que pudiera emerger de su contenido. Siquier no crea objetos intocables, autónomos, acabados, sino pinturas impuras e inestables. Sus obras, al igual que la de numerosos artistas contemporanoes, objetan la jerarquía del alto arte y rebaten así la distribución angosta y exclusivista del poder interpretativo. Urge examinar esta nueva apertura.

"Siempre pinté el mismo fucking cuadro", dice Siquier. ${ }^{1}$ Su afirmación es sorprendente. Uno de los artistas más importantes e innovadores de la Argentina contemporánea, Siquier, al explicar su pintura, se aferra a la repetición y descarta el valor de la originalidad. Su obra ataca, en efecto, el primado de lo único y plantea en cambio el dinamismo de la repetición.

Siquier pinta, sí, pero sus pinturas se alejan radicalmente de las tradiciones inveteradas del medio pictórico. Siquier despliega en cada pintura patrones que se vuelven a plegar y replegar en otras de sus pinturas. Se ampara en la repetición y quita por ello el foco de la fijación, de la determinación. Si bien, al parecer, la evolución de su obra es lineal, acompañando el paso del tiempo, Siquier opera de un modo circular que podría repetir hasta el infinito. Ciertas cuestiones y motivos persisten en sus pinturas y reverberan a través de ellas. Y a pesar de tal reiteración, esas cuestiones y motivos no son modelos purísimos y acendrados, irreducibles, sino que sufren diferenciaciones. Se actualizan en cada cuadro; se integran y se resuelven en composiciones en las cuales se afectan unos a otros. "No me identificaría con una definición de lo esencial como algún grado de limpieza o pureza", comenta Siquier. Agrega: "Buscaría la verdad en la mezcla, la combinación, la contaminación de formas y estilos". ${ }^{2}$

Se desprenden de sus palabras dos consideraciones. Primero, la obra de Siquier no propugna una verdad única y aboga, en cambio, por la multitud (e invita a los espectadores tanto a la interpretación de esa multitud como a la observación de cada pintura particular con la conciencia del aquí y ahora). Segundo, a pesar de desarrollarse en loop, existen en su obra variaciones. Entre los cambios más notables, se destacan la pérdida gradual del color y el empleo de la geometría como herramienta de control (para ordenar el gesto expresivo a inicios de los años noventa) y luego como descontrol (para romper enfáticamente con toda grilla, orden o sistema a fines de los noventa y en los 2000).

La pintura 0618 (2006) muestra una densa e intrincada construcción. Espacio y tiempo parecen haber sido compactados y pugnan ahora por sol- 
tarse y salirse. ${ }^{3}$ El lienzo no está uniformemente cubierto de pintura. La laboriosa composición tiene bordes: parece presentar una suerte de escudo. ${ }^{4}$ Pero si la heráldica por definición refiere a otra cosa, ¿qué significan los blasones de esta pintura?

Los patrones de 0618, copiosos y yuxtapuestos, están tachados por líneas arrebatadas que los convirtieron en miríadas de fragmentos. Nada, o casi nada, permaneció indemne a esta tormenta lineal. Quedaron apenas resquicios de patrones, por ejemplo, los restos de los círculos concéntricos que se replican en tantas otras pinturas de Siquier. Son residuos que son doblemente resquicios, porque solo se perciben a través de su sombra y porque, además, están tachados.

0618 trata el problema de la ilusión espacial en la pintura. El color negro marca la proyección de sombras y genera la percepción figura/fondo sobre el plano. Por lo tanto, no es posible circunscribir la obra a una reflexión respecto de la bidimensionalidad pictórica. A pesar de la obliteración y la dificultad, hay indicación de ciertos objetos identificables. Los patrones bien podrían aludir a la ornamentación de las fachadas de ciertos edificios, a la parrilla de un automóvil Cadillac o Chevrolet, a la tipografía y otros arquetipos del diseño gráfico e industrial. Además, la pintura podría ser la imagen de la fluidez turbulenta de las ciudades de hoy, aceleradas y caóticas. Sin embargo, son estas meras conjeturas, porque la obra no provee de remisiones directas, certeras, sobre su sentido. Ni el título ayuda. Se trata de un código que indica solo el año en que se realizó la obra (2006) y el orden dentro del año (la número 18 pintada entonces).

0618 es extraña. Está conformada por el desbordamiento de energía, patente en la pulsión de la tachadura, tanto como por el control regulatorio que ejerce el armazón simétrico subyacente. En esta pintura, las antípodas se juntan. Restricción y liberación, espacios positivos y espacios negativos, abstracción y figuración. Su fusión es desapaciguante.

El deseo de entender lo que vemos es básico, innegable, y Siquier explota este deseo con imágenes de subversiva inestabilidad. No crea formas herméticas, sin referentes, ni tampoco pinta mensajes evidentes, obvios. Atrae pese a la lectura turbia, velada, dudosa. Atrae sin seducir. ${ }^{5}$ Siquier mitiga las alusiones indiscutibles, dedicándose a crear, en sus palabras, "una suerte de ruido blanco". ${ }^{6}$

La rara atracción que genera Siquier se siente en las cuatro series en que se divide su obra. La primera se desarrolló entre 1985 y 1989, cuando el artista combinaba colores estridentes para lograr telas de gran intensidad. La segunda se desenvolvió entre 1989 y 1993, cuando trabajó efectos lumínicos para que las formas simularan poseer relieve. Pintó los fondos de
3 La reproducción de la obra 0618 (2006, Acrílico sobre tela, $198 \times 300 \mathrm{~cm}$.) puede contemplarse en la Web: https:// www.flickr.com/photos/pablosiquier/3079859597/. Consulta: Jul. 2017.

4 En efecto, esta composición tiene bordes, y tiene una estructura. No se trata de un diseńo all over, puesto que el lienzo no está uniformemente cubierto de pintura y no se observa un continuo sin foco o centro de atención. Es posible advertir un eje vertical en el centro de 0618 que crea la ilusión de simetría axial. Así, parece existir correspondencia en el tamaño y la posición de los círculos y de las borlas en el extremo inferior, y existirían también juegos entre lo cóncavo y lo convexo en los dispositivos dentados ubicados en cada uno de los laterales.

5 Apropio en esta oración palabras del propio Siquier, quien señaló en innúmeras entrevistas, así como en conversaciones conmigo, que el objetivo final al cual se ordena su práctica artística es el logro de una "atracción sin seducción". Por otra parte, Ernst Gombrich se ocupó del deseo de entender lo que vemos e investigó la relación entre la percepción visual y la representación pictórica, explicando el placer del reconocimiento del mundo que ya nos resulta familiar en el arte, y justificando así la mímesis o la "conquista de la realidad" a través de la pintura. De acuerdo con Gombrich: "En cuanto a la importancia del reconocimiento para el arte, puedo remitirme a una autoridad venerable [...]. Aristóteles, en el siglo IV a.C., discute en su Poética por qué la imitación causa placer al hombre que, como cortésmente admite, no es exclusivo de los filósofos profesionales. 'Disfrutamos contemplando estas representaciones porque, al mirarlas, aprendemos y deducimos lo que es cada una: por ejemplo, eso es tal cosa'. El placer, en otras palabras, deriva del reconocimiento [...]. Sabemos cuando reconocemos, y decimos, en palabras de Aristóteles, 'esto 
es tal cosa', y si no reconocemos, reclamamos el derecho a criticar". GOMBRICH, Ernst. H. La imagen y el ojo. Nuevos estudios sobre la psicología de la representación pictórica, 1987, pp. 14-15.

6 SIQUIER, Pablo. "Ciudad, trama y subjetividad”, Ciclo Diálogos con Artistas, organizado por la comisión de cultura de la Asociación Analítica Argentina. Web. www.youtube.com/watch?$\mathrm{v}=\mathrm{YJ} \mathrm{rCzCy}-\mathrm{QM} 4$. Consulta: ene. 2015.

\footnotetext{
7 Rafael Cippolini comentó que Siquier está en un "trip autista” u "ostracismo interior", en tanto Inés Katzentein lo caracterizó como el "creador de un programa de barroco apolíneo" y Arturo Carrera escribió que curte el "carpe noctem". Cf. CIPPOLINI, Rafael. Pablo Siquier, 2001; KATZENSTEIN, Inés. "Líneas y contrapuntos de una colección en proceso", 2007; CARRERA, Arturo. "Carpe Noctem de Siquier”, 2005.
}

8 La reproducción de la obra 8806 (1988, acrílico y óleo sobre tela, $130 \times 130 \mathrm{~cm}$.) puede contemplarse en la Web: https:// www.flickr.com/photos/pablosiquier/2919454132/. Consulta: Jul. 2017. un valor promedio, ni cálido ni frío, en pos de incrementar el impacto de las figuras constituidas con líneas negras que representan la sombra y líneas blancas que representan la luz. La tercera serie, iniciada en 1993, continúa en la actualidad (se divide en dos fases, la segunda de las cuales está en progreso y emergió a partir de la cuarta serie, o sea, hubo un relapso, Siquier burló la sucesión temporal). Se eliminó el color del fondo de las pinturas y, entonces, la luz se fundió con el blanco de base. Quedaron en las composiciones las líneas negras de las sombras. Los patrones u objetos ya no se ven, se insinúan, pero no están allí. La cuarta serie comenzó en 2003, cuando Siquier trabajó con las fuerzas opuestas de la perfección (evidente en dibujos precisos generados con la computadora) y la vaga inexactitud (al ejecutar murales con esos dibujos como base, en carbonilla, un instrumento endeble, poroso y discontinuo).

Siquier fijó parámetros para sí mismo al iniciar cada una de estas series y los mantuvo constantes, inmutables, durante el proceso de creación de las obras, que se extendió por años. Estableció el modo en que presentaría los contenidos sobre la superficie pictórica, por ejemplo, mediante la proyección de una luz imaginaria en el extremo superior derecho del plano (como ocurre en la segunda y tercera serie) o mediante la utilización de la perspectiva tradicional con punto de fuga central (como ocurre en la cuarta serie). Determinó también el procedimiento o material con el cual realizaría las obras de las series, por ejemplo, con carbonillas o creando líneas finas con pincel. Observó estos parámetros con rigurosa constancia y su persistencia le valió entre los críticos motes como el del artista en un "trip autista" o en un "ostracismo interior", el "creador de un programa de barroco apolíneo", o el pintor que curte el "carpe noctem" porque se repliega en sí mismo para mantener estables sus normas y, por ende, no establece mayores contactos con el resto de las personas que viven el día. ${ }^{7}$

Abordaré las series de Siquier para exhibir las reiteraciones que existen en su práctica pictórica. En las telas de la primera serie, Siquier pintó con colores saturados y sobre fondos muy trabajados. En 8701 (1987), por ejemplo, se observa un gran círculo central sobre el que se yerguen cuatro vectores rojos pintados en rojo intenso que se asimilan a las barras de una reja y cierran la composición, aunque también podrían ser las patas de algún animal fantástico. La figura principal de la pintura 8806 (1988) también es un círculo, resuelto a su vez con múltiples círculos concéntricos que crean la ilusión óptica de movimiento. ${ }^{8} \mathrm{El}$ disco resultante se recorta contra un fondo abierto y laxo: es un paisaje de tipo naturalista, en tonos fríos, en el cual predomina el cielo y, bien abajo, se ve una llanura verde que define la línea plana del horizonte. El disco, suspendido en medio de la pintura, conjura la idea de una visión, parece ser el producto de un trance espiritual 
o de un momento de éxtasis. Revela la incidencia en Siquier del arte de los enfermos mentales, cuyo influjo admite el artista, junto a la de los pintores autodidactas y el arte de los niños. Ocurre que durante los años de formación de Siquier, en la década del ochenta, reinaba en Buenos Aires una pintura de tipo expresionista en la cual él no se hallaba. Siquier se enfrentaba a una pintura que se proponía salvaje y espontánea, que buscaba exaltar la sensualidad de la materia y la subjetividad del pintor, pero que, en su iteración, se volvía formularia. Siquier recuerda: "Me resulta difícil insertarme en una tradición, justamente porque las tradiciones que me influenciaban eran ajenas a mí, era extranjero en estas y en las tradiciones de artes visuales no me sentía identificado”. En virtud de esa sensación de no identificación, debió recurrir a "todo lo que pasaba por fuera de la pintura" o directamente a lo "anticultural".?

Siquier se interesó por la música y los libros, y cuando exploró el arte, miró la obra de otros artistas que también se habían sentido acosados por la alienación y el desencanto: Joseph Beuys, Jean Dubuffet y Antoni Tàpies. Nótese que los tres son artistas que están dentro y fuera del canon, esto es, su obra se integra dentro del gran relato del arte del siglo XX, pero, simultáneamente, permite reflexionar sobre la diferencia y la otredad, y replantear así los límites del arte.

La posición anticultural de Dubuffet fue la que más influenció a Siquier. Dubuffet, quien acuñó la noción de Art Brut y descartó los conceptos del "logos" y la "belleza" heredados de la antigüedad clásica, buscó expresar al "hombre", y no a los derivados culturales occidentales arraigados en ese "hombre". Quiso presentar otro tipo de obras, que inhibieran en los espectadores los modos de recepción convencionales. Pensando en la "enfermedad" y en el Art Brut, Dubuffet comentó: "Cuando uno ha contemplado pinturas de este tipo, mira todo con ojos nuevos y refrescados, y aprende a ver los aspectos desapercibidos y graciosos de las cosas. Cuando digo gracioso, no me refiero solo al lado divertido de las cosas cotidianas, sino también a su costado grandioso, conmovedor y hasta trágico". ${ }^{10}$ Tal vez sea posible desplazar estas palabras a Siquier, porque él también buscaba refrescar el arte, refrescar la pintura que sentía agotada.

La segunda serie, que el propio Siquier denomina la "serie de los grises", muestra cambios significativos en relación con la anterior. Las pinturas de esta serie son obras más frías. Se ven mucho más ordenadas y la paleta de alto contraste ha desaparecido. Siquier parece haber descartado la noción de enfermedad, pero, como demostraré a continuación, no solo no es así sino que la enfermedad está asociada con la repetición característica de su obra.

Siquier pasó a pintar volúmenes esquemáticos ubicados de modo simétrico en lienzos con superficies lisas, sin marcas de pinceladas. El fondo de las pinturas respondió siempre al "gris 5", un valor promedio, ni cálido
9 SIQUIER, Pablo. "Mis influencias vinieron de la música y la danza, no vengo de la tradición pictórica”. Ramona, 2005, p. 88.

10 DUBUFFET, Jean. Prospectus. Cit. en Margit Rowell, Jean Dubuffet: A Retrospective, 1973, p. 23. De Dubuffet, la serie Hourloupe (1967-74) es la que más zonas de contacto tiene con la obra de Siquier. El término Hourloupe es un vocablo inventado sin sentido. La serie se basa en la proliferación de unidades, tipo células, que según Dubuffet creaban "una partitura ininterrumpida y resueltamente uniforme". El artista manifestó sobre estas obras: "Disolveré las categorías que nuestra mente emplea habitualmente para descifrar (o mejor, para cifrar) los hechos y espectáculos del mundo. La circulación de la mente de un objeto a otro, de una categoría a otra, será liberadora, su movilidad aumentará enormemente". DUBUFFET, Jean. Letter to Arnold Glimcher, 1969. Cit. en Rowell, Ibidem, p. 26. 
11 MESQUITA, Ivo. Pablo Siquier, 2005, p. 25. El subrayado es mío.

12 La reproducción de la obra 9202 (1992, acrílico sobre tela, 140 x $200 \mathrm{~cm}$.) puede contemplarse en la Web: https:// www.flickr.com/photos/pablosiquier/2919570034/. Consulta: Jul. 2017.

13 ESTOL, Leopoldo. "Entrevista", 2011, p. 66. ni frío, que adquirió tonos rosas, marrones, azules, verdes. Esta neutralidad incrementó el impacto de las figuras monocromas, configuradas por líneas negras que representan la sombra y líneas blancas que representan la luz.

A los espectadores, estas pinturas les podrían resultar exactas. Podrían sentir que Siquier calculó con rigor sus composiciones, sin dejarse llevar por ningún tipo de arrebato emocional. Sin embargo, en estas obras no prima el distanciamiento. Ivo Mesquita, organizó una importante exhibición panorámica de la obra de Siquier, observó:

\footnotetext{
Las pinturas de Siquier se constituyen a partir de una visión personal, fundada en la observación y en la vivencia de la ciudad, aliada a una sensibilidad neo-barroca, para revelar la inestabilidad de los signos, la ambigüedad del sentido y la difusión semántica que hacen funcionar la cultura urbana y las prácticas artísticas. Se trata por tanto de una obra que, con fuertes atributos formales, niega de forma paradójica el rigor del orden y de la razón que han regido parte del Modernismo histórico, para dar visibilidad a un mundo marcado por diferentes interacciones, con una diversidad de referentes, mutabilidad, polidimensionalidad y extrañamiento. ${ }^{11}$
}

La perfección -la salud exacta y racional de estas pinturas- no es más que una apariencia, un artificio de ocultación, porque la enfermedad sigue activa y sus síntomas se manifiestan en la paradoja y el extrañamiento que Mesquita percibió, y que ligó a una vivencia de la ciudad. En 9202 (1992), por ejemplo, es posible detectar esa contradicción o paradoja. ${ }^{12}$ La figura de esta pintura está subdividida en dos registros horizontales y múltiples registros verticales, reiterados, que intercalan luz y sombra, espacios abiertos o cerrados. Esta red de pilastras y entablamentos conforma una cuadrícula, el dispositivo paradigmático de los ejercicios formalistas en el arte, pero la obra sí contiene referentes, aunque enrarecidos, vueltos extraños. Remite a la arquitectura y la decoración de fachadas. No obstante, no está claro del todo a qué estilo arquitectónico pertenecería esta moldura o frontis rectangular (ni a los órdenes del neoclasicismo ni a la severidad del funcionalismo).

Sobre esta serie, Siquier comentó:

\footnotetext{
Siempre hubo edificios que me gustaron. Hay un balcón, me acuerdo, en San Telmo, que disparó toda la "serie de los grises". Era imposible que eso ocurriese, porque el balcón era tridimensional. Todo lo atractivo de esas ménsulas del balcón, que era medio decó, era imposible de reproducir en 2D. Pero de alguna manera vi eso y dije: "Acá hay algo, lo tengo que sacar a la cancha de alguna manera". ${ }^{13}$
} 
Siquier pintó patrones arquitectónicos que tomó de los edificios de Buenos Aires, aunque los alteró y les otorgó un aire de indeterminación. Además, al reconocer el interés de la arquitectura y el urbanismo, advirtió, también, que en la ciudad existía una "metástasis estilística", giro que él acunó para expresar un modo de mirar la mezcla, la impureza y la imperfección. Buenos Aires, en términos arquitectónicos, es un laboratorio a cielo abierto que permite comprender procesos de traducción y apropiación selectiva. Y Siquier se fascinó por la cornucopia de estilos que es o solía ser Buenos Aires (donde en un viaje en "colectivo" o autobús se podían ver, desde la ventanilla, edificios uno al lado del otro construidos en estilos bien diferentes, a pesar de su proximidad, o también fusiones estilísticas en un mismo edificio heterodoxo). El giro "metástasis estilística" da cuenta del modo en que el artista leía su contexto inmediato, focalizándose en la "arquitectura enferma”, la arquitectura transculturada que había intentado seguir los estilos europeos (estilos "sanos" o "puros" a los ojos dominantes), pero que había resultado en la selección e invención contaminada de estructuras, alzados, ornamentaciones. ${ }^{14}$

Pero Siquier no se limita a la mera representación de la arquitectura enferma, a copiar su impureza, sino que complica más sus mezclas, propagando patrones, conectándolos, duplicándolos, repitiéndolos. La iteración se multiplica en la obra 9112 (1991), compuesta por la yuxtaposición de muchas unidades prismáticas facetadas verticales. ${ }^{15}$ En la pintura 9103 (1991), esas mismas unidades prismáticas están sometidas a una nueva plegadura y aparecen en formato horizontal. ${ }^{16}$ Ambas obras revelan la existencia de una sintaxis repetitiva en la obra de Siquier, esto es, la exploración de los mismos motivos a través de varias pinturas. En estas obras la raíz etimológica del giro "metástasis estilística", relacionada con el latín infirmus, no firme, o ya falta de fuerza, se vuelve más evidente. Si se aplica esta carencia de firmeza al arte, no se hace más que ratificar la crisis la tradición pictórica. Lo "enfermo" que Siquier embandera, cuestiona aquí la confianza depositada en la especificidad de las obras maestras, esas obras únicas, originales, superiores, esas obras dominantes. Siquier, cuando reitera motivos, no genera una epidemia, más bien, lo que hace es inocular el virus de la pureza.

No obstante, las pinturas de esta segunda serie no están enraizadas solo en Buenos Aires (tanto como no responden tampoco solo al aspecto material, construido, de la ciudad, sino también a procesos sociales u políticos entramados en la urbe). Presentan además patrones con otros orígenes, como lo ejemplifica la obra 9709 (1994-1997), inspirada en parte en el Cenotafio a Newton proyectado por el arquitecto francés Étienne-Louis Boullée (1728-1799). ${ }^{17}$ Se alcanza a reconocer en esta pintura la esfera que proponía distinguir el monumento funerario, aunque Siquier la aplicó a
14 No es posible, para una porteña como yo, caminar frente a las obras del arquitecto Alejandro Virasoro, con sus estrías características aplicadas en las fachadas, o pasar por el edificio de oficinas Chacabuco 78, de Juan Jaime García Núnez, y mirar sus rejas con motivos en forma de pequeños círculos o puntos, sin recordar la pintura de Siquier. Son, por caso, dos arquitectos que entraban y salían de la modernidad, al emplear herramientas retóricas del vocabulario europeo mezclándolas con una perspectiva americana que resultó en estructuras híbridas. En este sentido, Nicolás Guagnini, al detenerse en el eclecticismo que rescatan las pinturas de Siquier, explicó: "El estilo en las culturas periféricas es justamente su colapso por melange, por contaminación involuntaria y por ausencia de proyecto sustentador. Es un meta-estilo bastardo que balbucea entremezcladas las lenguas exiladas de sus hermanos mayores del centro: los estilos puros, originales. Ese recurso al estilo fue el rasgo diferenciador imprescindible frente a la monotonía de la grilla implantadora de la ciudad y, mas allá, el abismo metafísico de la Pampa”. GUAGNINI, Nicolás. "La implacable sombra de la involución”. Ramona, 2005, p. 8. Texto publicado originalmente en el catálogo del envío nacional a la 26 Bienal de São Paulo en 2004, representado por Siquier.

15 La reproducción de la obra 9112 (1991, acrílico sobre tela, 130 x $200 \mathrm{~cm}$.) puede contemplarse en la Web: https:// www.flickr.com/photos/pablosiquier/2919570020/. Consulta: Jul. 2017.

16 La reproducción de la obra 9103 (1991, acrílico sobre tela, $150 \times 160 \mathrm{~cm}$.) puede contemplarse en la Web: https:// www.flickr.com/photos/pablosiquier/2919454210/. Consulta: Jul. 2017. Cabe anotar que en este juego entre reiteración y serialidad, estas pinturas remiten a la arquitectura, sí, pero también transparentan las inspiraciones 
musicales de Siquier, quien, al buscar expresiones culturales alternativas a las de la pintura de su tiempo, se había sosegado en las composiciones contemporáneas de Iannis Xenakis, Brian Eno y, sobre todo, Steve Reich.

17 Si se contempla la importancia que la enfermedad reviste para Siquier, no debe llamar la atención su atracción por Boullé, a quien sus contemporáneos consideraron "un espèce de fou en architecture" [una suerte de arquitecto loco]. Boullée trabajó durante la transición del ancien régime a la Revolución Francesa, y sus diseńos presentan una amalgama de elementos heterogéneos. Se despegan del barroco y se orientan al neoclasicismo, cuyas formas geométricas austeras, más elementales, Boullée animó con contrastes lumínicos. Habló de una "architecture des ombres", otro aspecto muy relacionado con la pintura de Siquier. Cf. KAUFMANN, Emil. "ÉtienneLouis Boullée". The Art Bulletin, 1939. Étienne-Louis Boullée realizó su dibujo Proyecto para Cenotafio a Newton en 1784; esta obra integra hoy la colección de la Bibliotheque Nationale de France, París.

18 ESTOL, Leopoldo. "Entrevista”, 2011, p. 69.

19 La reproducción de la obra 9813 (1998, acrílico sobre tela, $160 \times 230 \mathrm{~cm}$.) puede contemplarse en la Web: https:// www.flickr.com/photos/pablosiquier/2919820946/. Consulta: Jul. 2017.

20 SIQUIER, Pablo. "Mis influencias vinieron de la música y la danza, no vengo de la tradición pictórica”. Ramona, 2005, p. 90. Con anterioridad a este cambio tecnológico, Siquier realizaba esquemas en papel milimetrado que transfería al lienzo. Sus herramientas de trabajo eran el lápiz, la regla, el transportador, el compás $y$, finalmente, el pincel. Construía otra base horizontal. Como en un juego especular desquiciado, esa gran media esfera, ubicada en estricta simetría axial, se refleja en cinco círculos más pequeños. Dos prismas facetados flanquean la media esfera y los círculos. Se trata de las mismas unidades que componen las obras 9112 y 9103, si bien esas unidades aquí, insertas en otro sistema, ganan nueva singularidad. Así, diversos elementos, repetidos de pintura en pintura, entran en diversas relaciones de determinación recíproca.

La tercera serie, iniciada en el año 1993, continúa en la actualidad. Es la "serie de blancos y negros" dividida a su vez en dos fases, la segunda de las cuales está en progreso y fue desarrollada a partir del trabajo realizado en la cuarta serie.

En estas pinturas, restan sólo las líneas negras representando las sombras. Los patrones en sí no se ven, fueron fundidos con el fondo blanco. Las obras carecen, además, de estabilidad simétrica. Siquier explotó la tensión. Comentó: "Creo que el trabajo se puede definir como una indagación compositiva, una y otra vez. De qué manera ir en contra del equilibrio. Un residuo de esa atracción y fascinación por lo anticultural. De alguna manera, rompiendo con la composición armónica y equilibrada quería dar cuenta de alguna rareza, de alguna extrańeza." ${ }^{18}$ Esa rareza está presente en la intrincada construcción observada en la pintura 0618.

La intensa complejidad de esa obra aparece ya en un lienzo anterior, aunque de modo un poco más atenuado. 9813 (2001) presenta dos cuadrados en dos ángulos opuestos que crean una diagonal que carga de dinamismo a la composición. ${ }^{19}$ Uno de los cuadrados, en el ángulo inferior, se entrelaza con los dispositivos geométricos que avanzan desde el sector derecho de la obra. El otro cuadrado, en el ángulo superior, forma una suerte de cuadrícula compuesta por círculos grandes y pequeños. Esa cuadrícula quedó aislada, sola en el plano, como si fuera imposible mantener el orden que toda retícula históricamente reclama.

Sobre 9813, Siquier recuerda: "Es uno de los primeros cuadros que boceté con la computadora, así que para mí fue un cuadro de inflexión, de cambio en el sistema de producción, de las variables formales, seguía haciendo los mismos cuadros, siempre pinté el mismo cuadro, pero la computadora me permitió infinitas probabilidades." ${ }^{20} \mathrm{El}$ cambio metodológico potenció la reiteración. El proceso creativo de Siquier consiste fundamentalmente, como vimos, en la generación de motivos o diseños geométricos puntuales, y en un trabajo gramatical con esos motivos, combinándolos y generando variantes a partir de su repetición. Anotamos ya que estos motivos o diseños geométricos no son dispositivos formales netos, sino que poseen referencias, aunque nunca nítidas (se pueden rastrear en la arquitectura, en otros cua- 
dros del propio Siquier, en objetos de diseño industrial presentes en la vida cotidiana, en el tráfico de los automóviles por la ciudad o en los radiadores de los autos clásicos de los años cincuenta y sesenta, cuyas carreras veía Siquier en el autódromo, cuando era pequeño, junto a su padre).

Siquier conserva un archivo de sus motivos, en formato digital, en su computadora. Aseveró: "Tengo un elenco y lo llamo cuando lo necesito". ${ }^{21}$ En relación con esta afirmación, vale reparar en que el término "elenco" significa catálogo, pero se predica, además, de la nómina de una compañía teatral, y esta doble definición da cuenta del modo en que desde un medio, en este caso el pictórico, se mira a otro medio, el teatral, para explicar la constitución, la génesis misma, de una obra de arte.

A partir de la tercera serie, el trabajo de realización de las pinturas se inicia en la computadora. Frente a la pantalla, Siquier diseña la composición. Selecciona motivos y agrega más, más, más. Suma unidades. Arma yuxtaposiciones densísimas, siempre en la pantalla, hasta encontrar las alianzas, las conjunciones, las alteraciones adecuadas. Hasta recordar: le mot juste. Siquier dice evocar esta frase de Gustave Flaubert al decidir el momento justo en el cual concluir el diseño de cada obra, cuando ya repitió, transformó y reapropió sus motivos, cuando ya los desterritorializó y reterritorializó, y si los siguiera reiterando alcanzaría la implosión total de la pintura. ${ }^{22}$

Quizás en la cuarta y última serie, denominada simplemente "carbonillas", no importe tanto la fuerza de la multiplicidad sino el desbaratamiento de la lógica binaria exactitud/imprecisión. ${ }^{23}$ Siquier diseña andamios, cimbras, planos para edificios (en la computadora con un programa vectorial) y luego los dibuja a gran escala directamente sobre los muros (a mano, con carbonilla). A la distancia, la retina de los espectadores puede recomponer la precisión del diseño original pero, de cerca, debido al trazo poroso y endeble de la carbonilla, se ven en estos murales granulados, pequeños errores. Con el tiempo, el polvo de la carbonilla se disipará, y entonces quedarán solo marcas precarias o las fotografías de las obras.

El artista Nicolás Guagnini, autor de uno de los textos más lúcidos sobre la obra de Siquier, no dudó en afirmar: "Siquier no es un pintor". ${ }^{24}$ ¿Cómo explicar esta aseveración negativa? ¿Por qué Siquier es un pintor que no pinta?

Primero, importa anotar que no sorprende que sea otro artista quien escriba sobre Siquier, ofreciendo su interpretación en reemplazo de los habituales textos redactados por críticos y curadores. Es que Siquier es en Buenos Aires un artista de culto, él es "un artista de artistas". Ocupa un lugar de máximo respeto entre sus pares. Su obra funciona como un gozne que articula la admiración de artistas no solo de diferentes generaciones, sino con paciencia líneas de $1,5 \mathrm{~cm}$ de ancho para construir después la sombra que esas mismas líneas proyectaban. El compás viabilizaba pocas curvas.

21 Pablo Siquier en conversaciones conmigo, el 6 de diciembre de 2010 , en el marco de un encuentro con los estudiantes de la New York University en Buenos Aires.

22 Jorge Luis Borges consideró la célebre frase le mot juste y comentó: "En el caso de Flaubert, bueno, él fue escritor, y ejerció aquello como un sacerdocio, ¿no? [...] Hay una frase muy linda de él: Je refuse d'hater ma sentence; o sea, 'Me rehúso a apresurar mi frase'. Es decir, él trabajaba una frase, y hasta que no estuviera perfecta él no seguía adelante [...]. Él se encerraba en esa actitud que llamaba propia de su naturaleza; leía y releía en voz alta las frases, él dedicó su vida a eso". BORGES, Jorge Luis. "Flaubert", 2005, p. 292. Esta vocación de "sacerdocio" que Borges reconoció en Flaubert podría relacionarse con el "ostracismo interior", el "barroco apolíneo" y el "carpe noctem" que la crítica reconoció en Siquier.

23 Nicolás Guagnini reconoció el vaivén entre estos conceptos, el modo en que las carbonillas desarman polaridades, avanzando una interpretación provocadora, vinculada a la identidad nacional y la poscrisis. Según Guagnini:

"La pesadilla neoliberal de la que el 'caso' Argentina se convirtió en postal se refleja tanto en la autoritaria perfección modélica de las arquitecturas imaginarias representadas como en el default a la exactitud de tal modelo que el uso de materiales primitivos impone. Por otra parte, si ejecutar cuadros es, en la lógica del arte como mercancía, generar valor, realizar murales efímeros al carbón es como emitir moneda sin respaldo (o como mínimo se constituye en una crítica al valor)". GUAGNINI, Nicolás. "La implacable sombra de la involución”. Ramona, 2005, p. 9. Por otra parte, María Gainza también percibió vacilación en estas obras 
al reconocerles una "cualidad oscilante entre monumentalidad y pequeñez". GAINZA, María. "Los andamios del mundo". Página 12, 2004. Web. http://www.pagina12.com.ar/diario/suplementos/ radar/9-1683-2004-09-19.html. Consulta: ene. 2015.

24 Guagnini abrió su texto con estas reflexiones, acentuando su importancia, y continuó luego su argumentación recurriendo al condicional para expresar probabilidad, mas no certeza, sobre los "medios" que le podrían corresponder a Siquier: "Si debiéramos enmarcar su práctica en un episteme disciplinario, es claramente un dibujante, y como dibujante más bien un diseñador". GUAGNINI, Nicolás. "La implacable sombra de la involución". Ramona, 2005, p. 8. Texto publicado originalmente por Cancillería Argentina en el catálogo del envío nacional a la 26a Bienal de São Paulo en 2004, representado por Siquier (última edición de esa bienal en admitir envíos nacionales). Siquier posteriormente comentó: "Con Nicolás nos conocemos hace mucho tiempo y ese texto refleja muchas discusiones que llevamos hace mucho, es un texto que me describe claramente". SIQUIER, Pablo. "Mis influencias vinieron de la música y la danza, no vengo de la tradición pictórica”, Ramona, 2005, p. 87.

\section{Fabián Lebenglik recordó el} comentario de Noé al presentar el libro Pablo Siquier en ArteBA, 2011. MACCHI, Jorge. "Una visión de levedad que se transforma en una sensación de horror", Ramona, 2005, p. 69. Rosario Zorraquín en conversaciones conmigo, el 14 de febrero de 2015.

Siquier ocupa un lugar de máximo respeto entre sus pares porteńos. Varios motivos explican esta posición privilegiada. En primer lugar, Siquier fue interlocutor, desde joven, de otros artistas entonces emergentes y hoy consagrados como Ernesto Ballesteros, Ana Gallardo, Enrique Ježik y Jorge Macchi (con algunos de ellos integró el Grupo de la X, fundado en 1987 por artistas identificados como la "joven generación"). embarcados en modos de trabajo diversos. Luis Felipe Noé, por ejemplo, un pionero de los años sesenta, comentó que le gusta la obra de Siquier porque le gusta el caos, pese a la aparente precisión o frialdad formal. Algo similar manifestó Jorge Macchi, colega generacional, cuando confesó sentir placer frente a sus pinturas, si bien sabe del trabajo "obsesivo" y hasta "carcelario" que conlleva realizarlas. La joven Rosario Zorraquín describió la obra de Siquier como un virus que se reproduce cuadro a cuadro y, así, con este símil entre pintura y organismo vivo, dijo mucho sobre la actualidad de Siquier y su capacidad de reacción frente al mundo. ${ }^{25}$

Luego, sobre todo, las obras de Siquier no se insertan con docilidad dentro de la definición de la pintura porque sus lienzos no son cerrados, cohesivos o concretos. Esto es, Siquier pone en cuestión el estatuto de la obra de arte, no ya su originalidad, sino directamente su singularidad, la seguridad de sus bases, sus cimientos ontológicos. Impugna la tradición pictórica que sostuvo buena parte de la historia del arte: la pintura imaginada como una ventana perfectamente delimitada al mundo; el plano pictórico como el soporte de una construcción racional, contenida, terminada. Siquier, en lugar de presentar obras acabadas, ofrece repeticiones y sutiles diferencias que centellean a lo largo del tiempo en un juego sin conclusión. Y esta apertura es imposible de reducir a categoría o determinación alguna. En su obstinada irreducibilidad, en el rechazo a la fijación, la pintura de Siquier evade las simplificaciones -que siempre son manipulaciones- del pensamiento y la sociedad unidimensional. Las propias palabras de Siquier revelan como él se enfrenta a la lógica de aquel arte que busca representar con nitidez el mundo de lo dado. Según el artista: "Cuando me acerqué al arte, de pequeño, era por lo que tenía de extrańo e incomprensible. El arte ahora es positivo y constructivo. A mí me atrae más su condición oscura y negativa”. ${ }^{26}$ Siquier se acoge a la fuerza abrasiva de la negatividad, una fuerza que es tan disruptiva como creadora.

\section{Referencias}

BECCE, Sonia. Talismán se busca. Buenos Aires: Ruth Benzacar, 2009.

BORGES, Jorge Luis. "Flaubert". En : BORGES, Jorge Luis y FERRARI, Horacio. En diálogo. México: Siglo Veintiuno, 2005.

CARRERA, Arturo. "Carpe Noctem de Siquier". En: MESQUITA, Ivo (Ed.). Pablo Siquier. Madrid: Museo Nacional Centro de Arte Reina Sofía, 2005.

CIPPOLINI, Rafael. Pablo Siquier. Buenos Aires: Fondo Nacional de las Artes, 2001. 
ESTOL, Leopoldo. “Entrevista”. En: TABAROVSKY, Damián (Ed). Pablo Siquier. Buenos Aires: Adriana Hidalgo, 2011.

GAINZA, María. "Los andamios del mundo”. Página 12. 19 sep. 2004. Disponible en: http://www.pagina12.com.ar/diario/suplementos/radar/9-1683-2004-09-19. html. Consulta: ene. 2015.

GOMBRICH, Ernst. H. La imagen y el ojo. Nuevos estudios sobre la psicología de la representación pictórica. Madrid: Alianza, 1987.

GUAGNINI, Nicolás. "La implacable sombra de la involución”. Ramona 4. Marzo de 2005 .

KATZENSTEIN, Inés. Arte contemporáneo. donaciones y adquisiciones Malba. Buenos Aires: Fundación Costantini, 2007.

KAUFMANN, Emil. "Étienne-Louis Boullée”. The Art Bulletin. Septiembre de 1939.

MACCHI, Jorge. "Una visión de levedad que se transforma en una sensación de horror". Ramona 50. Mayo de 2005.

MALBRÁN, Florencia. Pablo Siquier. Buenos Aires: Aguilar, 2015.

MESQUITA, Ivo. Pablo Siquier. Madrid: Museo Nacional Centro de Arte Reina Sofía, 2005.

ROWELL, Margit. Jean Dubuffet: A Retrospective. New York: The Solomon R. Guggenheim Foundation, 1973.

SIQUIER, Pablo. "Mis influencias vinieron de la música y la danza, no vengo de la tradición pictórica”. Ramona 50. Mayo 2005.

“Ciudad, trama y subjetividad”, Ciclo Diálogos con Artistas, organizado por la comisión de cultura de la Asociación Analítica Argentina. Disponible en: www.youtube.com/watch? v=YJ rCzCy-QM4. Consulta: ene. 2015.

TABAROVSKY, Damián (Ed). Pablo Siquier. Buenos Aires: Adriana Hidalgo, 2011.
Luego, ganó enorme respeto en virtud de su activo desempeño docente, incentivando la creación de arte provocador, innovador. Dictó no solo "clínicas de obra” en su taller, sino múltiples seminarios en el interior del país, y enseñó en el Instituto Universitario Nacional del Arte, la Universidad de Buenos Aires y la Universidad Torcuato Di Tella. En 2010, el Centro Cultural Recoleta celebró su labor docente en la exhibición "Beuys y más allá. El enseñar como arte”. Según Elio Kapszuk, curador de la exhibición: "Siquier cumplimenta un rol en la enseńanza que promueve la horizontalidad en el intercambio. La posición no jerárquica es un componente importante de sus investigaciones relacionadas con la crítica institucional y la producción de arte, según la cual, la actitud contemporánea preferida es más la de participante que la de estudiante". Centro Cultural Recoleta. Web. www.centroculturalrecoleta.org. Consulta: ene. 2015. Un año antes, en 2009, la galería Ruth Benzacar había presentado la exhibición "Talismán se busca (parte II)”, organizada por la curadora Sonia Becce quien había tomado la inquietante obra 8806 (1988) como piedra angular para articular "un recorrido por algunas producciones de artistas de distintas generaciones vinculados a la pintura metafísica”. Cf. BECCE, Sonia. Talismán se busca, 2009. Por otra parte, los innúmeros artículos sobre Siquier, e incluso escritos por él, aparecidos en Ramona, una revista fundamental durante los años de su publicación, entre 2000 y 2010 , escenifican el papel central de Siquier en la escena nacional.

26 Cit. en MALBRÁN, Florencia. Pablo Siquier, 2015, p. 2. 